\title{
Corporate Responses in an Emerging Climate Regime: The Institutionalization and Commensuration of Carbon Disclosure
}

\author{
ANS KOLK*, DAVID LEVY** and JONATAN PINKSE* \\ *University of Amsterdam Business School, the Netherlands and ${ }^{* *}$ University of Massachusetts, \\ Boston, USA
}

\begin{abstract}
This paper examines corporate responses to climate change in relation to the development of reporting mechanisms for greenhouse gases, more specifically carbon disclosure. It first presents some background and context on the evolution of carbon trading and disclosure, and then develops a conceptual framework using theories of global governance, institutional theory and commensuration to understand the role of carbon disclosure in the emerging climate regime. Subsequently, a closer look is taken at carbon disclosure and reporting mechanisms, with a particular focus on the Carbon Disclosure Project (CDP). Our analysis of responses shows that CDP has been successfully using institutional investors to urge firms to disclose extensive information about their climate change activities. However, although response rates in terms of numbers of disclosing firms are impressive and growing, neither the level of carbon disclosure that CDP promotes nor the more detailed carbon accounting provide information that is particularly valuable for investors, NGOs or policy makers at this stage. As a project of commensuration, carbon disclosure has achieved some progress in technical terms, but much less with regard to the cognitive and value dimensions.
\end{abstract}

Correspondence Address: Ans Kolk, University of Amsterdam Business School, Roetersstraat 11, 1018 WB Amsterdam, the Netherlands. Fax: +31 20525 5281; Tel.: +31 20525 4289. E-mail: akolk@uva.nl

Published by Routledge Journals, Taylor \& Francis Ltd on behalf of the EAA. 


\section{Introduction}

Corporate responses to climate change have shifted dramatically over the past two decades. Until the early 1990s, business generally neglected the issue, though a few larger transportation and oil firms tracked the growing scientific attention on the topic. By the mid-1990s, North American businesses in sectors related to fossil fuels had woken up to climate change and perceived the prospect of greenhouse gas (GHG) emission regulations as a substantial threat. New industry groups were created, such as the Global Climate Coalition (GCC) and the Climate Council, which directed their energies toward preventing an international regime to impose caps on GHG emissions, and played a major role in preventing the USA from joining the Kyoto Protocol (Levy and Egan, 2003). The response from European business was slower in coming, less coordinated and less hostile, and they became receptive to climate measures at an earlier stage (Kolk, 2001; Kolk and Levy, 2004). More recently, business has tended to converge on a more constructive stance that acknowledges the scientific concerns and frames climate change as an opportunity rather than a burden (Margolick and Russell, 2004). This more optimistic view is expressed in a 2006 report from Ceres, a coalition of investors, firms and environmental organizations:

Companies at the vanguard no longer question how much it will cost to reduce greenhouse gas emissions, but how much money they can make doing it. Financial markets are starting to reward companies that are moving ahead on climate change, while those lagging behind are being assigned more risk.

(Cogan, 2006, p. 1)

As firms move from an oppositional political response toward preparation for a carbon-constrained future, they display a wide range of strategies (Kolk and Pinkse, 2005). Investing in low emission products and technologies is one core element, exemplified by BP's investment in solar energy as part of its new 'Beyond Petroleum' strategy. Firms are also seeking to reduce emissions from their operations, including transportation and buildings. Wal-Mart is focusing on these operational efficiencies, and the CEO recently stated that reducing greenhouse gases would 'save money for our customers, make us a more efficient business, and help position us to compete effectively in a carbon-constrained world' (Lash and Wellington, 2007, p. 96). Another core element of corporate strategy for climate change is development of the organizational and informational infrastructure for assessing, measuring, reporting and managing GHG emissions and their associated impacts. As emissions trading emerges as the primary policy response to the threat of climate change, business has intensified its development of GHG accounting and management capabilities in order to establish baselines, measure actual emissions and budget for the future purchase (or sale) of emission credits. Simultaneously, business is under increasing 
pressure from investors and environmental non-governmental organizations (NGOs) to disclose information related to their GHG emissions. NGOs are actively mobilizing large institutional investors in this respect with the argument that carbon disclosure represents information that is crucial for the more accurate valuation of assets. In turn, the information can also be used by NGOs to pressure firms to change their practices (O'Dwyer et al., 2005).

This paper examines the development of reporting mechanisms for greenhouse gases, more specifically carbon disclosure. We first present some background and context on the evolution of carbon trading and disclosure, and then develop a conceptual framework using theories of global governance, institutional theory and commensuration to understand the role of carbon disclosure in the emerging climate regime. Subsequently a closer look is taken at carbon disclosure and reporting mechanisms, with a particular focus on the Carbon Disclosure Project (CDP). We will analyse responses by the largest firms worldwide (the Financial Times 500 - FT500) to analyse the extent to which the institutional strategy of CDP to use investors as key point of leverage has been successful in urging firms to disclose extensive information about their climate change activities, and how valuable this has been in terms of institutionalization and commensuration, the latter defined as transforming 'qualitative relations into quantities on a common metric' (Levin and Espeland, 2002, p. 121). Our analysis raises doubts about the value that carbon disclosure initiatives such as the CDP have for investors, NGOs or policy makers at this stage. Carbon accounting is not very useful in understanding the market and technological risks and opportunities facing various firms and sectors, while voluntary carbon disclosure remains inconsistent and difficult to interpret. As a result, in the current state of the carbon market and climate change regimes, it is still hard to examine the linkages between corporate climate change strategies, financial performance and GHG emission reductions.

\section{Emergence of Carbon Trading and Disclosure}

Carbon dioxide is the most important greenhouse gas arising from human economic activity, so regulatory measures to control the emissions of GHGs most directly threaten sectors that produce or rely on fossil fuels, including coal, oil, automobiles, power generation and airlines. Other energy-intense sectors include cement, paper, agriculture and aluminium. Potent greenhouse gases, such as methane, HFCs and SF6, are emitted in smaller quantities by agriculture, waste processing facilities, electric utilities and air-conditioning manufacturers. Despite the considerable attention given to potential economic opportunities, fossil fuel-related sectors still clearly face a substantial 'regulatory risk' from higher fuel costs and lower demand for energy-intense products (Wellington and Sauer, 2005). The prospect of changes in prices, technologies and demand patterns also presents firms with considerable 'competitive risk', as markets are disrupted and existing core competences become obsolete. It is not a 
simple matter, however, for firms to invest in research and development and move into new low emission technologies, as these frequently require radically different capabilities that threaten to open industries to new entrants (Anderson and Tushman, 1990; Christensen, 1997; Kolk and Pinkse, 2008). Solar energy, for example, requires expertise in silicon semiconductors rather than geology and organic chemistry, the existing core competencies of oil firms.

The threat of regulatory controls on carbon prompted a wide range of sectors to respond aggressively in the early 1990s. US-based firms were particularly active in challenging climate science, pointing to the potentially high economic costs of greenhouse gas controls and lobbying government at various levels (Gelbspan, 1997; Leggett, 2000; Levy and Egan, 2003). European industry responded somewhat later to the climate change issue and displayed a greater readiness to accommodate pressures from regulators and environmental groups. European firms also demonstrated a greater willingness than their US counterparts to invest in technologies, such as wind power and diesel cars, that would produce modest but relatively quick GHG emission reductions (Kolk and Levy, 2004; Levy, 2005).

By 2000, key firms on both sides of the Atlantic were converging toward a more accommodating position that acknowledged the role of GHGs in climate change and the need for some action by governments and firms. Firms in energy and transportation-related sectors began to invest substantial amounts in low-carbon technologies, and engaged in a variety of voluntary schemes to inventory, curtail and trade carbon emissions. Studies have pointed to a number of factors that account for the shift (Kolk and Levy, 2004; Levy, 2005). Most significantly, senior managers in these firms have interacted with each other quite frequently in various industry associations, conferences and climate negotiations, leading to some convergence in their perceptions of the climate issue and of their interests. In a sense, these global industries and the 'issue arena' of climate change itself have become more important institutional influences on corporate strategy than the home country environment (Levy and Kolk, 2002). The shifting corporate stance on climate change can also be linked to the evolution in the USA of new organizations supportive of a proactive industry role, such as the Pew Center on Global Climate Change. On the economic level, competitive pressures and interdependence have compelled firms to respond to each other's moves (Kolk and Levy, 2004; Levy, 2005).

Carbon trading, in various forms, has emerged as the centrepiece of the incipient global climate regime. Indeed, carbon trading has facilitated the convergence of business, governments, NGOs and key academic and professional constituencies around a somewhat fragmented, decentralized and marketoriented mode of carbon governance (Aulisi et al., 2005). In principle, carbon trading provides a flexible path to emissions reductions at relatively low cost, while offering profitable opportunities for firms who can develop technologies for emissions reductions at less than the carbon price. For business, carbon trading offers a degree of flexibility compared with regulatory mandates such as automobile fuel efficiency standards, and perhaps some room for manoeuvre 
in carbon accounting practices. Moreover, if prices for $\mathrm{CO}_{2}$ remain under about $\$ 35 /$ tonne, businesses in most sectors can take modest steps to reduce emissions from operational efficiencies and avoid immediate threats to their core business models. Carbon trading offers opportunities to financial firms. Point Carbon, a consulting firm, estimates that 4.2 billion tonnes of $\mathrm{CO}_{2}$ (and equivalents) will be traded globally in 2008, with a value approaching $\$ 100$ billion (Point Carbon, 2008). The growing likelihood that most industrial sectors will be subject to some form of emissions trading is stimulating firms across the industrialized world to develop the organizational, accounting and technical expertise to conduct emissions inventories, estimate costs of internal emissions reductions, track emissions across the supply chain and trade emission credits.

Carbon trading is also attractive to other stakeholders in climate governance. For governmental authorities, cap-and-trade systems impose a carbon price without the political costs of direct taxes. The market mechanism lends the carbon regime a semblance of depoliticization by distancing policy makers from direct decisions about allocation of emissions reductions and technology choices. NGOs find that carbon trading resonates with their 'win-win' story about the opportunities for firms who proactively address climate change. There is even a minor industry of lawyers, economists and other academics engaged in constructing, evaluating and analysing carbon trading.

The European Union emissions trading scheme (EU-ETS), which came into force in January 2005, mandates emissions accounting and trading for firms operating in Europe in particular sectors, but with various exclusions for smaller facilities and power plants. Prices fell to near zero in 2007 due to over-allocation of emission credits in the first budget period, but prices in early 2008 were around $€ 25 /$ tonne. In North America a patchwork of systems exists. In the absence of federal regulation, states have taken the initiative on climate change, and several multi-state systems are in various stages of design. The Regional Greenhouse Gas Initiative (RGGI), which will impose a mandatory cap-and-trade system on power plants in 10 North-eastern and Mid-Atlantic states, will commence in 2009. The Western Climate Action Initiative is a similar effort covering California and five other Western states in the USA and two Canadian provinces.

A number of voluntary carbon mechanisms have also been developed. The Chicago Climate Exchange (CCX) opened in October 2003, and by 2008 grew to over 70 firms who commit to reducing their emissions from North American operations and use emissions trading to meet these commitments. A larger group of associate members have smaller direct emissions but commit to offsetting them. Due to the voluntary nature of the cap, carbon prices have been very low, around \$3-5 per tonne of carbon dioxide during 2007 and 2008. Several reasons exist for firms to engage in voluntary trading. They might be anticipating mandatory controls, attempting to shape future trading systems, establishing baselines to gain credit for early action or hoping to gain competitive advantage through early trading experience. Many larger firms need to develop an emissions management system for their European operations. Participation in private 
voluntary schemes, such as the CCX could also deflect demands for mandatory restrictions. The market for carbon offsets is another form of voluntary carbon trading. Several small firms and non-profits, such as Atmosfair in Germany and TerraPass in the USA, now sell offsets to consumers and firms who wish to reduce their carbon impact. They purchase emission credits from a variety of sources, including official programmes such as the Clean Development Mechanism, voluntary initiatives such as CCX and other sources.

The growth of voluntary carbon trading has been accompanied by the rise of voluntary carbon disclosure. Several environmental groups have been exerting pressure on firms to track and report their emissions by asserting that carbon management and reporting provides a mechanism for managing and assessing climate-related business risks and opportunities (The Climate Group, 2005; Lash and Wellington, 2007). Sectors such as agriculture, insurance, tourism and real estate face potential risks from the physical impacts of climate change, such as rising sea levels and more frequent and intense storms. Fossil fuel-related sectors are recognizing that carbon constraints will generate significant impacts on markets and costs. Neglecting climate change can also subject firms to reputational risks and legal liability. Firms developing low emission products and technologies stand to prosper in a carbon-constrained environment. Investors have also become aware of these risks. Considering the financial, regulatory and environmental liability risks, some of the largest investment banks, including Citigroup, JPMorganChase and Morgan Stanley, have issued restrictive guidelines for new coal investments. Plans to develop more than 50 new coal fired plants in the USA have been frozen in the last two years due to a combination of environmental and investor concerns (Makower et al., 2008). Several initiatives have emerged that attempt to leverage the influence of institutional investors to create demand for carbon disclosure as an adjunct to conventional financial systems, with implications for asset valuations. Two of the most prominent are the Carbon Disclosure Project (CDP) and the Investor Network on Climate Risk (INCR).

CDP is an international collaboration of institutional investors concerned about the business implications of climate change. Launched in 2000, CDP maintains a London-based coordinating secretariat for institutional investors to gain insight into the climate risk profiles of the FT500 firms, though it now surveys a much larger and more international group of firms. By the end of 2007, CDP comprised 385 signatory investors with more than $\$ 40$ trillion in assets, including large investment firms such as Merrill Lynch and Goldman Sachs, and state pension funds. This represents very rapid growth from just 35 investors in 2003, with $\$ 4.5$ trillion in assets. It should be noted that there are no costs or carbon commitments for signatory investors. More than 1,300 firms responded to the survey in 2007 (CDP5), reporting on various aspects of their carbon management. The analysis of these data constitutes the empirical core of this paper. The CDP represents a voluntary effort to develop standardized reporting procedures for firms concerning their climate-related activities, in a form intended to 
complement annual financial accounts and provide information relevant to investors relating to the business risks and opportunities from climate change. These reports, it should be emphasized, are not the same as carbon accounting; carbon disclosure contains information on a wide range of climate-related activities, including measurement of emissions, organizational preparations, technological investments, and trading and offsets. Carbon accounting is a more precise, formal but narrower activity concerned with quantifying emissions that can be bought and sold in accordance with a particular set of legal standards and limits.

The INCR is a smaller US-based initiative of Ceres which started in 2003 with 10 investors ( $\$ 600$ billion in assets) and has now grown to about 60 , representing $\$ 5$ trillion in assets. As with the CDP, INCR encourages financial analysts, ratings agencies and investment banks to address climate risks and opportunities. INCR goes further, however, and secures commitments from the signatory investors. At the February 2008 summit, INCR launched an action plan with a goal of deploying $\$ 10$ billion in additional investment in clean technologies over the next two years, and to aim for a $20 \%$ reduction over a three-year period in energy used in core real estate investment portfolios.

\section{Conceptual Background: Institutionalization and Governance}

The advocacy of voluntary corporate carbon disclosure represents a form of institutional entrepreneurship geared toward leveraging carbon disclosure as a form of governance. Institutional entrepreneurship represents a 'political process that reflects the power and interests of organized actors' (Maguire et al., 2004, p. 658) in attempting to transform institutions. These efforts to change or transform fields can resemble social movements, whereby 'entrenched, field-wide authority is collectively challenged and restructured' (Rao et al., 2000, p. 276). In this process, 'field constituents are often armed with opposing perspectives rather than with common rhetoric. The process may more resemble institutional war than isomorphic dialogue' (Hoffman, 1999, p. 352). The institutionalization of carbon disclosure is a political project because it entails a change in the structures of corporate governance in a way that shifts attention toward environmental objectives and enhances the legitimacy and engagement of environmental NGOs in governance processes. Carbon disclosure can also be conceived as an effort to shift the broader field of governance of the energy system. Despite the assertions of a 'win-win' case for carbon disclosure, it is likely to meet resistance from actors who traditionally dominate corporate governance, primarily managers and shareholders, who might be concerned about intrusions into their autonomy, the costs of reporting and the pressure to take action that potentially compromises their market position.

Institutional entrepreneurs often operate from a position of relative weakness, with less access to the material resources and formal authority of the incumbent 'field dominants' who are more centrally positioned in existing institutional 
arrangements (McAdam and Scott, 2005). As a result, institutional entrepreneurs need to employ what Levy and Scully (2007) term 'strategic power' in order to change institutions; they need to analyse the existing field configuration and coordinate interventions in the economic, organizational and discursive elements of the field. For example, Ceres, the environmental group behind the INCR initiative, understood that the organization lacked the ability to create new laws on carbon disclosure, and that it would be difficult to directly convince firms of the need to invest resources in preparing carbon disclosure reports. The preparation of such reports requires significantly more technical skill and resources than for more general social performance reports. Ceres identified investors as a key point of leverage, because of their strategic role in the broader field of corporate governance and because they would potentially be looking for ways to incorporate carbon risks into financial valuations.

INCR and CDP pursued several discursive strategies to help institutionalize carbon disclosure as a routine practice. They framed carbon disclosure as an extension of carbon trading, part of a market-based system with broad support. Carbon reporting was portrayed as parallel, even integral to financial reporting, drawing from its legitimacy and regulatory mandate. They also invoked the broader win-win frame of corporate social responsibility and reporting, in asserting that better environmental performance would lead to better financial performance. These discursive and economic strategies in relation to carbon disclosure provided the basis for an organizational strategy to build an alliance with environmental groups, firms and investors.

Carbon disclosure represents a form of 'civil regulation' (Murphy and Bendell, 1999), a mode of corporate governance in which civil society actors employ information disclosure mechanisms to exert pressure on business to establish and comply with environmental and social norms and standards (Cormier et al., 2005). The strategic logic behind carbon disclosure is similar to that of the Global Reporting Initiative, an earlier initiative of Ceres (Brown et al., 2007). In its focus on highlighting the relationship between share price and climate strategy, while bypassing formal regulatory mechanisms of the state, carbon disclosure also constitutes a 'non-state market driven governance system' (Cashore et al., 2004, p. 4). These approaches to governance represent a strategic shift by NGOs toward the direct targeting of corporate practices rather than state regulatory policies, and reflect the growing interest in recent years in private, voluntary and market-oriented modes of governance (Prakash and Hart, 1999; Higgott et al., 2000; Utting, 2002). The institutionalization of standardized information disclosure is a key element of these governance systems, because it provides a channel for accountability to stakeholders, it enables them to demand certain performance levels, and it can be used for benchmarking and comparison. It thus offers reputational benefits for strong performers, while enabling NGOs to exert pressure on non-disclosers and poor performers (Florini, 2003; Fiorino, 2006). It also focuses managerial attention on improving the outcomes being measured. The annual publication of Toxic 
Release Inventory data in the USA is widely viewed as a successful example of information-based governance; though mandatory and contested by affected industries, it has been widely credited with inducing large reductions in toxic emissions from industrial plants (Graham, 2002).

The effort to enlist investors in the institutionalization of carbon accounting and management represents a sophisticated strategy on the part of environmental groups, but it is not a guaranteed mechanism. Strategic power is by its nature a contingent and indeterminate process (Levy and Scully, 2007). The efficacy of carbon disclosure relies on a particular chain of causal logic: the carbon reports need to be relevant and valuable to investors by conveying information that relates to the financial impact of climate risks and carbon controls on the valuation of corporate assets (Hassel et al., 2005). Investor scrutiny will then put pressure on firms to disclose information on their carbon profile and to take action to reduce emissions. Firms producing this information are expected to become more aware themselves of connections between their carbon profile and their financial performance. Furthermore, the strategy relies on NGOs and governments using the carbon disclosure information to pressure firms through benchmarking and ranking (O'Dwyer et al., 2005). These chains of causation may not materialize, however; reducing carbon emissions may not generate demonstrable financial gains, investors might find the information difficult to interpret and NGOs might not find disclosure reports particularly useful in their climate change strategies.

Crucially, the institutionalization of carbon reporting as a form of governance relies on a successful project of 'commensuration', defined by Levin and Espeland (2002, p. 121) as 'the transformation of qualitative relations into quantities on a common metric'. Just as financial reporting translates a firm's myriad activities into a common monetary metric, so carbon reporting attempts to render complex organizational operations involving multiple gases and impacts in terms of a common carbon metric, $\mathrm{tCO}_{2} \mathrm{e}$ (tonnes of carbon dioxide equivalent). The carbon market is not a naturally existing entity; the commodification of carbon is a political and institutional project, requiring an extensive legal and bureaucratic infrastructure to define and measure carbon units for various activities and gases, allocate and adjudicate property rights, and to establish rules for trading across national boundaries and different carbon jurisdictions. For example, carbon accounting systems need to specify the 'exchange rates' at which quantities of other greenhouse gases, such as methane and perfluorocarbons are commensurate with $\mathrm{CO}_{2}$. They need to establish procedures for setting emissions baselines from which reductions 'count'. The European Trading System and RGGI use disparate mechanisms and cover different sectors, yet rules are being developed to enable carbon trading across the systems. Reporting systems also need to specify which technologies and activities count toward emissions and reductions. These are, in part, technical questions. For example, the effectiveness and longevity of carbon sequestration through reforestation or compression and injection into old oil fields is difficult 
to determine. But these are also political questions, involving an asymmetric distribution of costs and benefits across actors. Emissions need to be allocated to particular actors and activities in the value chain; the $\mathrm{CO}_{2}$ released from driving cars could be attributed to an oil company, an automobile company or the final consumer.

Even if commensuration is successful in terms of the institutionalization of the norms and technical mechanisms for transforming GHG emissions into a common currency, this does not ensure an effective carbon governance regime that will secure the necessary reductions to stabilize the climate. Just as accounting regulations have not prevented firms from adopting practices to avoid taxes or move risks and liabilities to other entities, the politics of carbon commensuration provide a degree of flexibility in reporting and exempt entirely certain regions and sectors. For example, emissions from military activities and international air travel and shipping are exempt from the Kyoto Protocol process. Yet numerous firms compete to sell air travellers carbon offsets, and these offsets themselves are beset with accounting and verification difficulties (Bumpus and Liverman, 2008). Many of these offsets originate in projects in developing countries that reduce emissions from a somewhat arbitrary 'business as usual' baseline, and frequently the projects generate net emissions increases. Voluntary carbon trading without a firm and enforceable carbon cap results in low prices that provide little incentive for efficiencies or innovation (Gillenwater et al., 2007). Even mandatory trading programmes have their share of critics. Driesen (2003) has pointed out that they can suffer from complexity, uncertainty and high transaction costs. Far from being transparent market-based systems, they are subject to heavy lobbying from affected sectors, often resulting in numerous exemptions, over-allocation of permits and importation of credits from dubious sources. As a result, carbon prices tend to be low. Depending on how permits are allocated, various perverse and unintended incentives can arise (Baldwin, 2008).

Carbon disclosure, as promoted by the CDP and INCR, does not rely on the same strict form of commensuration required for carbon accounting and trading. It does, however, attempt a form of commensuration by enabling comparisons and rankings of carbon mitigation activities across firms and sectors, and the imputation of the market impact of carbon-related risks and opportunities. The CDP has given priority to increasing the standardization of reporting in successive versions of its survey. Without reporting tonnes of carbon, disclosure reports attempt to portray the extent to which firms are conducting carbon inventories, preparing for trading, investing in mitigation technologies and establishing managerial responsibilities. This commensuration effort does not require the precision of carbon accounting, but is more difficult due to the breadth and diversity of activities, and the qualitative nature of the data. Carbon disclosure entails a second form of commensuration in its endeavour to translate corporate carbon profiles into assessments of risks and market opportunities with clear financial implications for firms and investors. Indeed, this constitutes the central logic 
behind the carbon disclosure movement, so if commensuration is inadequate, the momentum behind carbon disclosure is likely to stall.

\section{Methods and Data}

To provide a closer look at carbon disclosure and reporting mechanisms, we analyse the process of disclosure as this occurs through the Carbon Disclosure Project (CDP). Our main aim is to shed light on what CDP can and cannot bring as an avenue of disclosure that is specifically aimed at climate change. We question to what extent carbon disclosure initiatives such as the CDP provide information that is valuable for investors, NGOs and policy makers. In other words, does CDP provide satisfactory information on the linkages between corporate climate change strategies, financial performance and GHG emissions reductions to enable such stakeholders to make decisions regarding a firm? In our analysis we use the conceptual framework developed above and particularly elaborate on the concept of commensuration to understand the role of carbon disclosure in the emerging climate regime.

As we already mentioned, the CDP has concentrated on requesting annual information from firms around the world on GHG emissions, in the process raising both corporate and investor awareness. As stated on its website, the goal of CDP is 'to create a lasting relationship between shareholders and corporations regarding the implications for shareholder value and commercial operations presented by climate change'. Moreover, CDP wants to 'facilitate a dialogue, supported by quality information, from which a rational response to climate change will emerge'. The first CDP inventory, published in 2003, only targeted the FT500; the latest one available at the time of writing (published in the fall of 2007) approached more than 2,400 firms. In the FT500 set, that was included in all five years, response rates have grown considerably over the years, from $46 \%$ in 2003 to $77 \%$ in 2007 . To keep the amount of data manageable in our analysis we focus on this FT500 set only; also because we expect firms in this set to have relatively well-developed responses as most of them have already been using this reporting avenue for some years now.

For the purpose of this paper we analysed the responses to CDP5, published in 2007. We first looked at the overall response of FT500 firms to assess whether CDP is a successful project of commensuration in the sense that it provides a reporting format that allows easy direct comparison across firms. Next, we focused more specifically on a set of questions containing components of particular relevance for assessing the value and relevance of carbon disclosure for investors, NGOs and policy makers. This encompassed, firstly, the question about greenhouse gas accounting to examine which GHGs are reported and whether this has been verified. Secondly, we examined the organizational and geographical scope of carbon accounting (direct and/or indirect GHG sources and location) to assess whether commensuration takes place throughout the whole organization or at selected environments with high institutional pressure only (e.g. places that 
have an emissions trading scheme). Thirdly, we assessed the extent to which firms translate their carbon exposure into financial figures such as costs or savings. To analyse the CDP data we used the QSR NVivo 7 software package. This program is particularly useful to manage the large quantity of data that we had, as the sample consists of 380 responding firms. The software package allows the rich nature of the qualitative data to be used, because it enables selecting large sections of texts in which codes are embedded. In addition, the data contained in the codes can be related to firm-specific attributes, such as country-of-origin and industry (Bazeley, 2007).

\section{Investor Pressure and the Institutionalization of Carbon Disclosure}

In terms of numbers, CDP has clearly been a very successful project for institutionalizing carbon reporting among the 500 largest firms in the world, as very high response rates were attained within a short period of time. In the FT500 set, that was included in all five years, response rates have grown considerably, from 227 firms (46\%) in 2003, 287 (59\%) in 2004, 351 (71\%) in 2005, 362 firms (72\%) in 2006 and 383 (77\%) in 2007. In other words, the vast majority of FT500 firms are now using CDP as a mechanism for carbon disclosure. Yet, these numbers also show that the increase in responses from 2003 towards 2005 has levelled off since.

Nevertheless, this trend in CDP response has seen some geographical variation. As Figure 1 indicates, the raw number of North American firms using

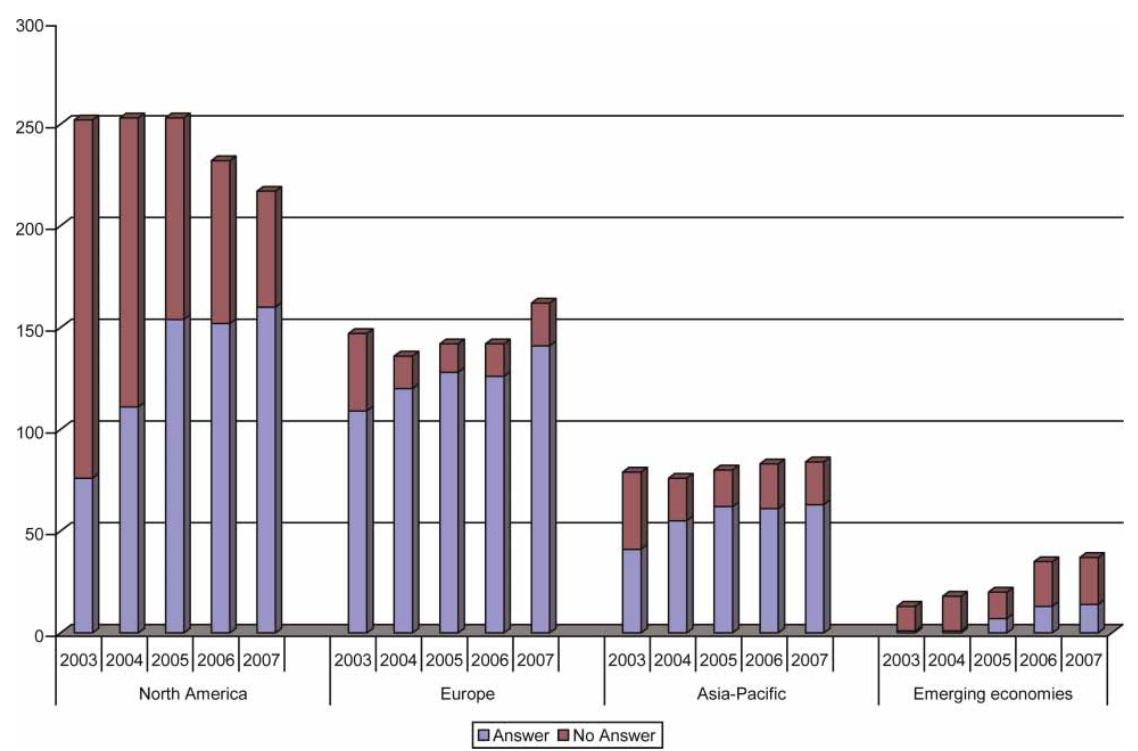

Figure 1. Geographical variation in CDP response. Source: Updated from Pinkse and Kolk (2009). 
CDP for carbon disclosure was initially lower than European firms, but they surpassed them by 2005 (it must be noted that the North American sub-sample predominantly consists of US firms). Nevertheless, percentages tell a different story. North American firms went from 30\% response in 2003 to 44, 61, 66 and 74\% in the following years, respectively. Response in Europe has been much higher as it moved from $74 \%$ in 2003 to just below $90 \%$ in the following years. What Figure 1 also shows is that large firms from emerging economies like Brazil, Russia, China and India are starting to enter the FT500, and also address climate change, with 14 responding firms in 2007 compared to only 1 in 2003.

As we argued above, the main way by which CDP has tried to help institutionalize carbon disclosure as a routine practice is by using institutional investors as key point of leverage. The investors that have been involved in CDP are almost all financial institutions, ranging from banks, insurance firms, pension funds and mutual funds to more specialized socially responsible investment (SRI) funds. However, although most of the relatively small group of institutional investors involved in the first cycle of CDP had some background in SRI (Financial Times, 2002), over the years the group has expanded to include many other institutions without a special SRI interest. On the face of it, CDP has been doing very well in binding institutional investors to its cause, as it received backing from prominent investment banks and pension funds. It must be noted, however, that for the institutional investors to participate in CDP, they merely have to act as signatory; CDP does not require disclosure of their own carbon mitigation activities or investments. There is also no charge to signatory investors.

To examine whether bringing into play investors as a means of institutional entrepreneurship has been successful, we compared the regional response patterns with the number of CDP signatories and the country from which they originate. In its yearly reports, CDP provides detailed information, including country of origin, on (almost) all of these investors. According to the reports published by CDP (2007, p. 14), in the period 2003-2007, the number of investors participating in CDP has increased from 35 in 2003 (with \$4.5 trillion in assets), 95 in 2004 (\$10.2 trillion in assets), 155 in 2005 (\$21 trillion in assets), 224 in 2006 (\$31.5 trillion in assets), to 310 in 2007 (with over \$41 trillion, representing more than one-third of total institutional funds worldwide). This is a clear indication that investor pressure to answer the CDP questionnaire has increased substantially, as reflected in the overall response rate. Table 1 shows that while initially most of these investors originated from the UK, the number of countries represented has grown considerably. The type of investors that participated clearly elucidates the geographical patterns above, in that it took some time for US and Japanese firms to start disclosing information about climate change to the same extent as their European counterparts. Particularly in 2003, US and Japanese firms hardly felt any pressure from investors from their home countries. The table also shows that in 2006 a substantial increase took place in participating investors in several specific countries. The reason is that in this year, CDP was extended beyond the FT500 as questionnaires were also sent out to the biggest 
Table 1. Investor participation in the period 2003-2007

\begin{tabular}{lrrrrr}
\hline $\begin{array}{l}\text { Geographical origin } \\
\text { of investor }\end{array}$ & $\begin{array}{c}2003 \\
n=32\end{array}$ & $\begin{array}{c}2004 \\
n=89\end{array}$ & $\begin{array}{c}2005 \\
n=147\end{array}$ & $\begin{array}{c}2006 \\
n=215\end{array}$ & $\begin{array}{c}2007 \\
n=310\end{array}$ \\
\hline Australia & - & $4(4.5)$ & $5(3.4)$ & $11(5.1)$ & $16(5.2)$ \\
Austria & - & - & - & $1(0.5)$ & $1(0.3)$ \\
Belgium & - & $3(3.4)$ & $2(1.4)$ & $2(0.9)$ & $2(0.6)$ \\
Brazil & - & - & $6(4.1)$ & $15(7.0)$ & $30(9.7)$ \\
Canada & - & $6(6.7)$ & $13(8.8)$ & $16(7.4)$ & $32(10.3)$ \\
France & - & $4(4.5)$ & $8(5.4)$ & $14(6.5)$ & $17(5.5)$ \\
Germany & $1(3.1)$ & $6(6.7)$ & $6(4.1)$ & $33(15.3)$ & $36(11.6)$ \\
India & - & - & - & - & $1(0.3)$ \\
Ireland & - & - & - & - & $1(0.3)$ \\
Italy & - & $2(2.2)$ & $5(3.4)$ & $3(1.4)$ & $3(1.0)$ \\
Japan & - & $4(4.5)$ & $12(8.2)$ & $13(6.0)$ & $15(4.8)$ \\
Mexico & - & - & $1(0.7)$ & - & $-11(3.5)$ \\
Netherlands & $2(6.3)$ & $8(9.0)$ & $10(6.8)$ & $10(4.7)$ & $11)$ \\
Norway & $1(3.1)$ & $1(1.1)$ & $2(1.4)$ & $3(1.4)$ & $7(2.3)$ \\
Philippines & - & - & $1(0.7)$ & $1(0.5)$ & $1(0.3)$ \\
South Africa & - & $1(1.1)$ & $2(1.4)$ & $3(1.4)$ & $5(1.6)$ \\
South Korea & - & - & $2(1.4)$ & $1(0.5)$ & $4(1.3)$ \\
Sweden & $3(9.4)$ & $2(2.2)$ & $4(2.7)$ & $7(3.3)$ & $10(3.2)$ \\
Switzerland & $2(6.3)$ & $5(5.6)$ & $7(4.8)$ & $8(3.7)$ & $11(3.5)$ \\
UK & $17(53.1)$ & $24(27.0)$ & $33(22.4)$ & $40(18.6)$ & $47(15.2)$ \\
USA & $6(18.8)$ & $19(21.3)$ & $28(19.0)$ & $34(15.8)$ & $52(16.8)$ \\
\hline
\end{tabular}

${ }^{\text {a }}$ Percentages in parentheses.

firms from some specific countries, including Australia, Brazil, France, Germany and Japan.

To put more emphasis on the fact that CDP clearly sees itself as representing the investment community, it has also tried to make the relation between investor pressure and response rates more explicit in its yearly reports. It has done so in the period 2004-2007 by reporting a 'wall of shame' with the names of non-responsive firms, and has linked them to the percentages of common shares held by investors attached to CDP. This is based on the expectation that firms with a relatively high share ownership by CDP signatories are more likely to feel pressured to disclose information about their carbon mitigation activities. In this period, this list of firms has predominantly consisted of US firms, although two Russian firms topped the list in 2007. For example, aircraft manufacturer Boeing was number four on the list in 2004 and even topped the list in 2005 (CDP investors owned 13.9 and $20 \%$ of Boeing in these years, respectively) (CDP, 2004, p. 39; 2005, p. 51). In the case of Boeing this 'shaming' pressure seems to have worked as it answered the questionnaire in 2006. Another remarkable example is US investment bank Morgan Stanley; while it had two consecutive top 10 listings on the 'wall of shame' in 2004 (\#7) and 2005 (\#2) (CDP, 2004, p. 39; 2005, p. 51), its subsidiary that manages institutional accounts - Morgan Stanley Investment 
Management - became one of the signatories for the fourth cycle of CDP. For the last two cycles, CDP also calculated the average share ownership by CDP signatories. For those firms that did not respond or declined to participate the average was $10 \%$ in 2006 and $11 \%$ in 2007; this was somewhat higher for those who provided full responses (14\% in 2006; $15 \%$ in 2007) or provided information (from company reports) (17\% in 2006; 16\% in 2007). In 2007, only 17 of the 110 firms that had $20 \%$ of ownership by CDP signatories failed to respond (11 out of 17 involved US firms) (CDP, 2007, p. 57).

The CDP response data thus suggests that shareholder pressure can have an impact on disclosure. This impact is clearly part of a broader movement that has started to pay attention to the risks and opportunities of climate change. The year 2006 saw, for example, a publication on corporate governance and climate change that ranked the world's largest 100 firms on the extent to which they integrate climate change in their governance practices and strategic planning (Cogan, 2006). Moreover, climate change has received most support amongst the CSR proposals filed by shareholders in the USA in the period 2001-2003 (Monks et al., 2004). In subsequent years, and as documented by CDP, the numbers are still increasing: from 22 filed in 2004 in the USA, to 42 in 2007 (CDP, 2007, p. 71). In that sense, current interest seems to be the culmination of a mainstreaming effort that started originally within the (more niche) SRI community, and with only a few firms that recognized the need to do something on climate change. However, notwithstanding the fact that CDP has successfully been using the strategic power of investors to mobilize the world's largest firms to disclose information about carbon mitigation activities, CDP also wants to be of value to these investors by providing them with corporate climate change information in a comparable format (CDP, 2007). In the next section, we will consider to what extent CDP has actually been successful in providing comparable and consistent information.

\section{Commensuration of Carbon Disclosure Reporting}

Even though the response rates are quite impressive, a closer look at the information that is disclosed by those firms that answered the questionnaire sheds a very different light on the apparent success of CDP. In the remainder of this paper, we will argue that effective commensuration still presents a major challenge, both on the level of carbon disclosure reporting that CDP promotes as well as the more detailed process of carbon accounting. For carbon disclosure reporting, commensuration is interpreted in a somewhat less strict form, in that it does not require complete quantification into a common metric of all qualitative relations, as Levin and Espeland (2002) define it. Nevertheless, what CDP does aim to achieve is to reach an adequate level of comparison to be able to rank firms on their carbon mitigation activities. For example, from the second cycle onwards CDP has compiled its own ranking, the Climate Disclosure Leadership Index, translating company answers into scores. If carbon disclosure cannot deliver 
comparable information, it will be complicated for investors to assess the financial impact of carbon mitigation activities across firms and the value of carbon disclosure will be negligible (Hassel et al., 2005). Moreover, if there are doubts about the reliability of the data (e.g. due to a lack of external verification), carbon disclosure will not be credible and consequently not meet user needs of other stakeholders like NGOs and policy makers (O'Dwyer et al., 2005). The extent to which CDP data is comparable and reliable for meeting the needs of investors, NGOs and policy makers has been questioned, based on observations that the data is frequently incomplete and inconsistent between firms and over time (Hesse, 2006; Kiernan, 2008).

The CDP5 questionnaire consists of four main components - risks, opportunities and strategy; GHG accounting; GHG management; and climate governance - all containing various more detailed questions. Most firms use a narrative style outlining all the initiatives that they have taken to combat climate change. This is particularly the case for answers to questions regarding opportunities, risks, strategy and governance. Since it is largely at the discretion of responding firms to decide which elements regarding their risk perception, opportunity recognition and ensuing strategies to disclose, it is very difficult to compare different firms on these dimensions. One reason is that the questions are formulated very broadly, instead of asking for an assessment of a specific and exhaustive list of climate-specific risks and opportunities. For example, although the two USbased utilities Exelon and FirstEnergy both state in their answers that they are well-positioned in having a relatively low risk exposure, it is still difficult to compare the two. While Exelon provides much detail about renewable energy projects in which it is engaged, FirstEnergy emphasizes investments in carbon sequestration as well as its nuclear generation capacity. Because these types of questions do not explicitly ask for precise financial figures on the impact of climate change on the firm, it is difficult to compare the risk exposures.

Moreover, the questions about risks, opportunities and strategy provide a platform for firms to showcase all kinds of climate-related projects that do not necessarily provide a faithful picture of the strategic stance of a firm on climate change. For example, although firms outline all kinds of potential risks such as regulatory risks (e.g. from emissions trading schemes), firms tend to stay silent on their lobbying activities to mitigate these risks (Hesse, 2006). To illustrate, while BMW mentions the plans of the European Commission to curtail $\mathrm{CO}_{2}$ emissions of cars and refers to a position paper by the European Automobile Manufacturers Association (ACEA) outlining the industry's objections to these plans, competitor Volkswagen is completely silent about the Commission's plans even though it is also an ACEA member. In other words, this suggests that Volkswagen, unlike BMW, has failed to disclose a material risk to investors (Hesse, 2006).

Part of the reason why CDP does not live up to its full potential is that the format of the questionnaire has been changing over the years. Responses have clearly evolved, partly as a reflection of changes in the questions posed to the 
firms. Over the years, the questionnaires have started to pay more explicit and specific attention to emissions trading (initially only a general question, but later mentioning the EU-ETS and CCX, and, in CDP4 and CDP5, also the Clean Development Mechanism and Joint Implementation); and to an increasing number of details related to strategy, governance and management, and to measurement and auditing. Overall, there has been a clear shift to greater emphasis on actual emissions and measurement and governance related to that.

However, this trend of putting more emphasis on quantitative (financial) information, has had mixed results. On the one hand, as we will indicate below, it has led to improvements in disclosure of GHG emissions. On the other hand, questions that probe for an estimation of the financial impact of carbon mitigation activities have produced somewhat meagre results. To begin with, CDP asked what cost savings firms have achieved as a result of their emission reduction programmes. Of the total sample of 380 firms, only 27 produced a financial figure estimating these cost savings. While most others just fail to answer the question, some give a reason for this. One firm mentions that their reduction programme is too recent to provide reliable results, another sees problems in separating these costs from the overall operating budget and a few state that this information is confidential. Similar arguments are mentioned with regard to a question on total energy costs, and then particularly that this information is confidential. Nevertheless, a substantial number (123 firms) do provide an estimation of total energy costs and/or an indication of the share of energy costs as a percentage of total revenue. Still, it is difficult to compare such data as the final figure depends on the methodology used to estimate these costs. Several oil and electricity firms mention that part of their energy use is self-generated. Since no market price is attached to this form of energy consumption, they argue that it is very complex to estimate one consolidated figure. Finally, CDP asks for the total number of EU-ETS allowances received and the impact of this trading scheme on their profitability. While 76 firms disclose their total number of allowances, only a few mention the cost of compliance or the revenue from selling excess allowances. However, the common thread of the answers about the impact of the EU-ETS is that the costs and/or revenues are marginal and therefore not material to profitability.

Besides the difficulty of disclosing financial impact in a way that does justice to the complexity of estimating such figures, the mere fact that CDP has tried to improve the questionnaire also means that it has become more difficult to make analytical and comparative sense of the firm responses over time. For example, each year the questionnaire has been different as CDP added and removed certain (sub) questions, and rephrased recurring ones, leading to somewhat different responses by firms, even if the theme of a particular question remained largely the same. For example, CDP4 contained for the first time a question about the extent and means by which firms communicate about climate change in their annual report and other channels, but just one year later this question had vanished. Interestingly, several firms even neglected the 
fact that the questionnaire had changed, and just answered the question from the preceding year. Another trend, adopted since CDP4, is the use of sub-questions. This has further impeded comparability because many firms just respond to the overarching question without paying notice to these sub-questions. There is basically not a single firm that answers each sub-question contained in the questionnaire. On the whole, CDP suffers from similar problems as those seen in environmental reporting, with so much missing data that on many issues it is impossible to make a fair comparison between firms (Larrinaga et al., 2002).

Another problem is that, in an effort to improve comparability, CDP has tried to make a distinction between sectors, with more information requested from carbon-intensive sectors. For example, CDP4 included a separate section for those questionnaires sent to utilities. However, this did not really work because many utilities chose to simply ignore it. In CDP5 there was, for the first time, one set of questions for all firms (which covered risks, opportunities and strategy; and greenhouse gas emissions accounting), and an additional set for a specific group of firms more significantly affected by climate change or GHG emissions, who were asked for additional details on GHG emissions accounting and management, and climate change governance. However, it is not always clear to which group a firm belongs, as this is self-defined. This is particularly a problem in moderately carbon-intensive sectors. To illustrate, in the electronic equipment producers sector, firms including Emerson Electric, Nortel Networks and Philips have chosen to answer the short version, because they do not see themselves as carbon-intensive, while some of their competitors like Canon, Matsushita, Sharp and Siemens side with the group of firms that is significantly affected by climate change. Consequently, what occurs is that within the same sector the amount of information disclosed differs significantly between related firms, due to the different perceptions of their vulnerability to climate change.

\section{Commensuration of Carbon Accounting}

Over the past five years carbon accounting has become a prominent part of the CDP questionnaire. It is this component of carbon disclosure reporting that holds the most promise of becoming a successful project of commensuration. However, compared to the commensuration of carbon disclosure reporting, commensuration of carbon accounting is a more contentious process with more farreaching short-run consequences for the development of the carbon market. Even though carbon disclosure reporting is still failing to integrate figures on the financial impact of carbon mitigation activities adequately, as we argued in the previous section, the consequences of this lack of commensuration are still unclear because it is not known to what extent investors actually use the data from carbon disclosure reporting in their investment decisions. By contrast, the lack of commensuration in carbon accounting is less ambiguous, since 
transforming carbon mitigation activities into a common metric is the main foundation of the carbon market (Levin and Espeland, 2002). In the case of trading schemes, the allocation of allowances usually depends on historical emissions or, in some cases, on some form of industry benchmark. It is therefore critical that emissions are measured in a consistent way across firms.

Levin and Espeland (2002) argue that a process of commensuration has three distinct dimensions: a technical, value and cognitive dimension. With regard to climate change, technical commensuration entails translating emissions of various greenhouse gases into one common carbon metric, $\mathrm{tCO}_{2} \mathrm{e}$ (tonnes of carbon dioxide equivalent). What this requires is coming to an agreement on how to reckon with the fact that there are several GHGs $\left(\mathrm{CO}_{2}, \mathrm{SF}_{6}, \mathrm{CH}_{4}\right.$, $\mathrm{N}_{2} \mathrm{O}$, HFCs and PFCs) which have different global warming potentials. For example, one outcome of technical commensuration is that it is agreed upon that methane $\left(\mathrm{CH}_{4}\right)$ has 25 times the potential of $\mathrm{CO}_{2}$ (over a 100-year time horizon) and HFC-23 14,800 (IPCC, 2007). Value commensuration involves attaching a price to reductions of these different GHGs from different sources and occurs within the framework of an emissions trading scheme (e.g. the EU-ETS or the CCX) or climate change registry (e.g. the California Climate Action Registry or the Canadian GHG Challenge Registry). Finally, cognitive commensuration means coming to a common understanding of the meaning of pollution, the identity of the polluter and the emissions a firm is responsible for. For example, is it the end-user, the electric power provider or the fuel supplier who is responsible for the $\mathrm{CO}_{2}$ emissions that result from electricity consumption? Moreover, cognitive commensuration also involves a spatial and temporal dimension regarding whether one unit of emission reduction in one place or point in time is valued the same as one achieved at a different location or point in time (Levin and Espeland, 2002).

Key to achieving commensuration in carbon accounting is the adoption of a widely accepted methodology to transform all kinds of polluting activities into corresponding emissions. For this purpose, only in the past few years have several standards and protocols emerged that facilitate tracking and registering firms' GHG emissions. Currently, the most widely used standard is the WBCSD/WRI GHG Protocol which was first launched in 2001 and renewed in 2004. Deutsche Telekom mentions, for example, that even though they are currently not using it, they 'strongly believe that the GHG Protocol will be the future standard'. CDP also advises reporting firms to use this GHG Protocol, which has led to 197 firms stating that they used it for disclosing GHG emissions in CDP5. The main feature of the GHG Protocol is that it distinguishes between direct and indirect emissions by subdividing these in different scopes. Direct or Scope 1 GHG emissions come from sources that a firm owns or controls. This generally includes emissions from fossil fuel combustion for electricity, heat or steam generation, production processes for cement and steel manufacture, transportation by company-owned vehicles or airplanes, and fugitive emissions, such as refrigerants and methane (Phillips, 2004). Under regulations such as the 
EU-ETS, it is specifically (part of) these Scope 1 emissions for which a firm is held accountable, and, not surprisingly, these types of emissions are reported most widely in CDP5 (253 firms). The main reason for firms not to disclose this kind of data systematically is that they do not have measurement systems in place; moreover, in the absence of regulation, there seems to be no real necessity to implement such a system (CDP, 2007).

Indirect emissions, on the other hand, come from sources where the point of release is not within the firm itself, but either upstream or downstream in the supply chain. Within the category of indirect emissions a distinction is made between Scope 2 emissions from the consumption of electricity purchased from an upstream generator and Scope 3 emissions from other sources not owned or controlled. Whereas Scope 2 emissions are still well defined, this is not the case with Scope 3 emissions, because it is at a firm's discretion how far up and down the supply chain emissions are tracked. Reporting of Scope 2 emissions is almost completely in line with Scope 1, with 235 firms reporting these emissions. Scope 3, on the other hand, is reported less often, only 146 firms in CDP5. Examples of activities that fall under Scope 3 are extraction and production of purchased materials and fuels, transport-related activities, outsourced activities, use of sold products and services, and waste disposal (WRI/WBCSD, 2004). Lower disclosure of Scope 3 is not surprising as the GHG Protocol sees this as optional. What is more, firms tend to only report on a few types of activities that fall under Scope 3 emissions. The most widely reported Scope 3 emissions are from employee business travel; these are estimated by 99 firms.

Although the wide adoption of the GHG Protocol would suggest much progress towards technical commensuration of GHG accounting, this number is somewhat misleading. A closer look at the methodology that firms use for making an emissions inventory reveals that the GHG Protocol is often used in combination with another measurement methodology, for example, to establish the conversion factors by which fossil fuels like oil, coal and gas are converted into $\mathrm{CO}_{2}$ emissions. Examples are conversion factors provided by the UK Department for Environment, Food and Rural Affairs (DEFRA) and Intergovernmental Panel on Climate Change (IPCC). Besides, the GHG Protocol is often not used directly, but only forms the foundation of customized guidelines, for example, the EPA Climate Leaders GHG Inventory Guidance and guidelines proposed by the International Petroleum Industry Environmental Conservation Association (IPIECA) and the American Petroleum Institute (API). CDP answers suggest that particularly oil producers use methodologies customized to their own industry. In addition, there are also some competing protocols, such as the California Climate Registry General Reporting Protocol, the Canadian Association of Petroleum Producers (CAPP) guidelines and methodologies developed by Japanese ministries. Some firms do not use the same methodology worldwide, but adapt the methodology to the specific location. For example, German utility E.ON uses the European Commission Monitoring and Reporting Guidelines 
for emissions under the scope of the EU-ETS, while at the same time in the USA adopts the GHG Protocol. This clearly shows that commensuration is not only a technical exercise, but also a social and political process (Levin and Espeland, 2002). Firms belonging to a particular organizational field, for example, global oil firms, adopt their own institutional logic about what emissions are important and how to measure these by constructing their own methodologies.

One of the difficult issues in achieving cognitive commensuration is deciding which emissions firms are responsible for. Regarding direct emissions, the selection of sources depends on the consolidation method, because organizational boundaries affect which activities are owned or controlled. Amongst those firms that report on their organizational boundaries, there is an even mix between reporting based on consolidated financial statements, entities over which the firm exercises control and entities owned by the firm. A result of these different ways of setting organizational boundaries is that emissions may be double counted by more than one firm or not counted at all. The only instances when these boundary issues are settled to some extent are when value commensuration takes place within the framework of an emissions trading scheme. When property rights and prices are attached to emissions, firms are forced to adopt a specific institutional logic regarding the measurement of emissions. Things become more problematic, however, if we move beyond the direct emissions from firms' own production activities. The assignment of emissions becomes muddied then because the organizational boundaries in case of indirect emissions from purchased electricity, supply chain or transportation of products are not so straightforward. These issues have not yet been settled with formal accounting rules as these emissions are generally not taken into account in emissions trading schemes.

Cognitive commensuration also relates to the definition of pollution and the types of emissions to be reported. In CDP5, firms only report a consolidated (global and Annex B) figure in $\mathrm{CO}_{2}$. It is unclear whether this also includes non- $\mathrm{CO}_{2}$ emissions. Results from earlier cycles are not encouraging because, even though this was asked for at the time, firms tended to ignore other GHGs such as methane, often using the argument that emissions of these other gases are almost negligible. Nevertheless, given the larger global warming potential of many of the other GHGs, not disclosing this information may not be justifiable. Other issues that stand in the way of comparability are of a spatial nature: are all global locations of a multinational included and is geographical information about emissions by country available? CDP asks firms to report global emissions as well as emissions generated in Annex B countries (countries with a Kyoto commitment). In total 274 firms report global emissions, while 193 refine this figure to reflect Annex B emissions. Still, data about organizational scope show that global emissions are often not truly global but reflect a large but incomplete part of firm emissions. Moreover, even though CDP asks for it, only 86 firms provide a breakdown of emissions per country, and sometimes this offers 
no more detail than the home country and 'the rest of the world'. Firms from Japan and the USA are more likely to just report emissions generated in their home country.

Such problems related to measurement and scope also have their impact on the auditing of emissions. Although 189 firms mention auditing or verification, responses show considerable diversity in interpretation. In some cases, the CSR or sustainability report was said to be verified by an external party (which could be an auditing or consulting firm or NGO), but this was sometimes just referred to in general, or as auditing of the reporting process, or more specifically with regard to the emissions data (frequently without giving details about the outcome of it). In other instances, firms stated that a specific component of the overall emissions profile was checked; this could be the data in the home country only or in another particular location. The influence of strong, local institutions is clearly seen as several utilities mention that they require external verification because they fall under the EU-ETS, but unfortunately this also means that verification often does not go beyond these local boundaries. At best, this usually means that just a portion of the total emissions data has been audited. Sometimes, firms answered this question even more broadly by referring to an audited environmental management system, to internal auditing processes or to the intention to commence verification sometime in the future. In some instances there was no reference to auditing at all, perhaps attributable to the fact that the question on auditing/verification of data was one in a set of questions under the 'methodology' heading. The lack of external verification compromises the credibility of carbon accounting and thus raises serious doubts about the usefulness of the information to stakeholders (O'Dwyer et al., 2005).

Recent developments in carbon accounting reflect a growing convergence toward a limited set of methodologies, with the GHG Protocol taking a dominant position. This implies that there has been quite some progress in achieving technical commensuration. However, cognitive commensuration is far more difficult to achieve and more steps forward are still required. There continues to be a need for more clarity on how organizational boundaries are determined to designate the polluter, which GHG emissions should be measured and transparency on where emissions take place geographically. It now seems that the only way that firms are forced to adopt common methodologies on these issues of cognitive commensuration is when they operate within a framework of an emissions trading scheme that deals with the final step of achieving value commensuration. However, as long as the EU-ETS is the only large trading scheme, value commensuration will not take place on a global level. Even though CDP tries to have global coverage and uses institutional investors as leverage, this still remains a weak form of pressure, and by itself could never achieve value commensuration. This suggests that only the backing of coercive pressures from governments could achieve this final step, although in the field of environmental reporting doubts have been raised as well whether regulation will induce full disclosure (Larrinaga et al., 2002). 


\section{Discussion and Conclusions}

In this paper we have examined the development of reporting mechanisms for greenhouse gases, based on a conceptual framework using theories of global governance, institutional theory and commensuration to understand the role of carbon disclosure in the emerging climate regime. We paid specific attention to the Carbon Disclosure Project, which originated in the UK with strong participation of UK institutional investors. While it has broadened over the years to include more investors from other regions as well, the analysis of response patterns shows that European firms have been most active in completing the questionnaires, although the gap with North American and particularly Japanese firms has narrowed in recent years. CDP has clearly been very successful in terms of the numbers of reporters and backing from prominent investment banks and pension funds. In some ways, this reflects successful institutionalization and a process of global convergence.

However, although response rates have been quite impressive, a closer look at the information that is disclosed by those firms that answered the questionnaire sheds a different light on the apparent success of CDP. We have argued that commensuration is still lacking both on the level of carbon disclosure reporting that $\mathrm{CDP}$ promotes as well as the more detailed process of carbon accounting. As to the contents of firms' responses to the CDP, which can be seen as a form of civil regulation, it should be noted that the comprehensibility of carbon disclosures is still questionable. The frequent lack of disclosure of types and meaning of emissions data, and of reliability checks, means that it is very difficult to get insight into reported emissions, let alone firms' actual achievements. Even experienced analysts of climate change and emissions data find it very hard to make sense of firm reporting as part of CDP (Kiernan, 2008). A 2006 discussion paper that took some examples of responses to the CDP questions, from the perspective of a financial analyst/ institutional investor, found several discrepancies and answers that seemed implausible, thus raising questions about usefulness, for investors in particular (Hesse, 2006). Hence, in spite of increasing response rates and expanding volume of the answers, there is no real evidence that the information is helpful and is being used by investors in their decision-making processes (Kiernan, 2008). This broader form of value commensuration is far from successful institutionalization. The fact that participation in CDP imposes no requirements on the signatories has helped to attract large numbers of investors, but has not led to a more committed and binding relationship between information 'users' and disclosing firms.

If even experts struggle, then it will be much more complicated for 'lay' observers unfamiliar with the field. While attempts to include a key indicator on the financial implications and other risks and opportunities of climate change in sustainability reports seeks to address this problem (GRI, 2006; cf. Habbitts and Gilbert, 2007), the current difficulties in adequately disclosing such information 
for CDP offers few grounds for optimism in this respect. A similar problem exists in assessing whether climate change strategies are having an effect in reducing corporate impacts. On the basis of its fourth survey, CDP (2006) tentatively concluded that high-impact sectors such as utilities, oil and gas, and metals and mining generate most emissions and that the trend shows increasing emissions in these sectors. This does not bode well for corporate responses to climate change in the current epoch, in spite of all attempts to increase accounting and reporting.

Nonetheless, this also means that there certainly is much room for improvement as it is a dynamic and expanding field attracting high levels of attention from the public, the media, government and business. This applies particularly to those sectors for which the issue is highly salient because they are most confronted with it, and those specialized in goods or services that can help firms to respond or mitigate their impacts (cf. Kolk and Pinkse, 2008). Beyond that, the introduction in the investment community of carbon beta and related environmental indices that explicate the variance between firms, both between and within sectors, may, if successful, encourage investment decisions that take carbon risks and opportunities into account, using carbon beta baskets for example (Kiernan, 2008). The need for stricter carbon disclosure which follows clear guidelines that do not vary per year and require external verification, also to ensure comparability and the provision of all relevant data (so no incomplete information), might become more prominent as a result, as this is an essential input for good decision making. Where such pressure for monitoring and rigour needs to come from is obviously the question. Likely candidates may be the investment community - once they become convinced about the carbon beta premium - and particularly policy makers - but this seems to require a global regime and/or more widespread carbon trading. Until this is the case, commensuration of carbon reporting and accounting is still far away.

From a research perspective, the growing availability of data, even with their limitations, provides opportunities for more in-depth investigations of corporate responses to climate change, both more generally and specifically with regard to carbon accounting and reporting. Expected forthcoming emissions trading regimes, at various levels, will provide a further incentive for firms to extend their disclosure, management and accounting related to climate change, thus yielding input for studies into business and climate change in various respects. Nevertheless, the quality of the information, and especially the drive to link incomplete and unchecked (since self-reported) climate change information to (financial) performance is something researchers should be cautious with, also because some firms are more likely to respond to questionnaires than others, thus leading to unrepresentative samples. It is in this area and at this stage in particular that accounting researchers can play an important role in helping to put things in the right perspective. 


\section{Acknowledgement}

We thank the reviewers, the editor and guest editors for their feedback on earlier versions of this paper. Ans Kolk and Jonatan Pinkse would like to acknowledge the Netherlands Organisation for Scientific Research (NWO) for financial support.

\section{References}

Anderson, P. and Tushman, M. L. (1990) Technological discontinuities and dominant designs: a cyclical model of technological change, Administrative Science Quarterly, 35, pp. 604-633.

Aulisi, A., Farrell, A. E., Pershing, J. and VanDeveer, S. D. (2005) Greenhouse Gas Emissions Trading in U.S. States: Observations and Lessons from the OTC NOx Budget Program (Washington, DC: World Resources Institute).

Baldwin, R. (2008) Regulation lite: the rise of emissions trading, Regulation \& Governance, 2, pp. 193-215.

Bazeley, P. (2007) Qualitative Data Analysis with NVivo (London: Sage).

Brown, H. S., de Jong, M. and Lessidrenska, T. (2007) The rise of the Global Reporting Initiative (GRI) as a case of institutional entrepreneurship, Corporate Social Responsibility Initiative Working Paper No. 36, John F. Kennedy School of Management, Harvard University, Cambridge, MA.

Bumpus, A. G. and Liverman, D. M. (2008) Accumulation by decarbonisation and the governance of carbon offsets, Economic Geography, 84 (2), pp. 127-155.

Cashore, B., Auld, G. and Newsom, D. (2004) Governing through Markets (New Haven, CT: Yale University Press).

CDP (2004) Carbon Disclosure Project 2004 (London).

CDP (2005) Carbon Disclosure Project 2005 (London).

CDP (2006) Carbon Disclosure Project 2006 (London).

CDP (2007) Carbon Disclosure Project 2007 (London).

Christensen, C. M. (1997) The Innovator's Dilemma: When New Technologies Cause Great Firms to Fail (Boston: Harvard Business School Press).

Cogan, D. C. (2006) Corporate Governance and Climate Change: Making the Connection (Boston, MA: Ceres).

Cormier, D., Magnan, M. and van Velthoven, B. (2005) Environmental disclosure quality in large German companies: economic incentives, public pressures or institutional conditions?, European Accounting Review, 14(1), pp. 3-39.

Driesen, D. M. (2003) The Economic Dynamics of Environmental Law (Cambridge, MA: MIT Press).

Financial Times (2002) A niche sector tries to punch above its weight, 23 August, p. 5.

Fiorino, D. J. (2006) The New Environmental Regulation (Cambridge, MA: MIT Press).

Florini, A. (2003) The Coming Democracy: New Rules for Running a New World (Washington, DC: Island Press).

Gelbspan, R. (1997) The Heat is On (Reading, MA: Addison-Wesley).

Gillenwater, M., Broekhoff, D., Trexler, M., Hyman, J. and Fowler, R. (2007) Policing the voluntary carbon market, Nature Reports Climate Change, 6, pp. 85-87.

Graham, M. (2002) Democracy by Disclosure: The Rise of Technopopulism (Washington, DC: The Brookings Institution).

GRI (2006) Sustainability Reporting Guidelines (Amsterdam: Global Reporting Initiative).

Habbitts, S. and Gilbert, S. (2007) Reporting the Business Implications of Climate Change in Sustainability Reports (Amsterdam: GRI/KPMG). 
Hassel, L., Nilsson, H. and Nyquist, A. S. (2005) The value relevance of environmental performance, European Accounting Review, 14(1), pp. 41-61.

Hesse, A. (2006) Climate and Corporations - Right Answers or Wrong Questions? Carbon Disclosure Project Data - Validation, Analysis, Improvements (Bonn/Berlin: Germanwatch).

Higgott, R. A., Underhill, G. R. D. and Bieler, A. (2000) Non-State Actors and Authority in the Global System (London: Routledge).

Hoffman, A. J. (1999) Institutional evolution and change: environmentalism and the U.S. chemical industry, Academy of Management Journal, 42(4), pp. 351-371.

IPCC (2007) Climate Change 2007: The Physical Science Basis - Contribution of Working Group I to the Fourth Assessment Report of the IPCC (Cambridge: Cambridge University Press).

Kiernan, M. J. (2008) Climate change and investment risk. Presentation at the Amsterdam Global Conference on Sustainability and Transparency, GRI, Amsterdam.

Kolk, A. (2001) Multinational enterprises and international climate policy, in: B. Arts, M. Noorman and B. Reinalda (Eds) Non-State Actors in International Relations, pp. 211-225 (Aldershot: Ashgate).

Kolk, A. and Levy, D. (2004) Multinationals and global climate change. Issues for the automotive and oil industries, in: S. Lundan (Ed.) Multinationals, Environment and Global Competition, pp. 171-193 (Oxford: Elsevier).

Kolk, A. and Pinkse, J. (2005) Business responses to climate change: identifying emergent strategies, California Management Review, 47(3), pp. 6-20.

Kolk, A. and Pinkse, J. (2008) A perspective on multinational enterprises and climate change. Learning from an 'inconvenient truth'?, Journal of International Business Studies, doi: 10.1057/ jibs.2008.61.

Larrinaga, C., Carrasco, F., Correa, C., Llena, F. and Moneva, J. M. (2002) Accountability and accounting regulation: the case of the Spanish environmental disclosure standard, European Accounting Review, 11(4), pp. 723-740.

Lash, J. and Wellington, F. (2007) Competitive advantage on a warming planet, Harvard Business Review, 85(3), pp. 95-102.

Leggett, J. (2000) The Carbon War: Dispatches from the End of the Oil Century (London: Penguin Books).

Levin, P. and Espeland, W. N. (2002) Pollution futures: commensuration, commodification, and the market for air, in: A. Hoffman and M. Ventresca (Eds) Organizations, Policy and the Natural Environment: Institutional and Strategic Perspectives, pp. 119-147 (Stanford: Stanford University Press).

Levy, D. L. (2005) Business and the evolution of the climate regime, in: D. L. Levy and P. J. Newell (Eds) The Business of Global Environmental Governance, pp. 73-104 (Cambridge, MA: MIT Press).

Levy, D. L. and Egan, D. (2003) A neo-Gramscian approach to corporate political strategy: conflict and accommodation in the climate change negotiations, Journal of Management Studies, 40(4), pp. 803-830.

Levy, D. L. and Kolk, A. (2002) Strategic responses to global climate change: conflicting pressures on multinationals in the oil industry, Business and Politics, 4(3), pp. 275-300.

Levy, D. and Scully, M. (2007) The institutional entrepreneur as modern prince: the strategic face of power in contested fields, Organization Studies, 28(7), pp. 971-991.

Maguire, S., Hardy, C. and Lawrence, T. B. (2004) Institutional entrepreneurship in emerging fields: HIV/AIDS treatment advocacy in Canada, Academy of Management Journal, 47(5), pp. 657-679.

Makower, J., Pernick, R. and Wilder, C. (2008) Clean Energy Trends 2008 (San Francisco: Clean Edge).

Margolick, M. and Russell, D. (2004) Corporate Greenhouse Gas Reduction Targets (Arlington, VA: Pew Center on Global Climate Change/Global Change Strategies International). 
McAdam, D. and Scott, W. R. (2005) Organizations and movements, in: G. F. Davis, D. McAdam, W. R. Scott and M. N. Zald (Eds) Social Movements and Organization Theory, pp. 4-40 (Cambridge: Cambridge University Press).

Monks, R., Miller, A. and Cook, J. (2004) Shareholder activism on environmental issues: a study of proposals at large US corporations (2000-2003), Natural Resources Forum, 28, pp. 317-330.

Murphy, D. F. and Bendell, J. (1999) Partners in Time? Business, NGOs, and Sustainable Development (Geneva: United Nations Research Institute for Social Development).

O'Dwyer, B., Unerman, J. and Hession, E. (2005) User needs in sustainability reporting: perspectives of stakeholders in Ireland, European Accounting Review, 14(4), pp. 759-787.

Phillips, G. (2004) Monitoring, verification and accounting of emissions, in: C. de Jong and K. Walet (Eds) A Guide to Emissions Trading - Risk Management and Business Implications, pp. 99-119 (London: Risk Books).

Pinkse, J. and Kolk, A. (2009) International Business and Global Climate Change (London: Routledge).

Point Carbon (2008) Carbon 2008. Post-2012 is Now (Oslo: Point Carbon).

Prakash, A. and Hart, J. A. (1999) Globalization and Governance (London: Routledge).

Rao, H., Morrill, C. and Zald, M. N. (2000) Power plays: how social movements and collective action create new organizational forms, in: B. M. Staw and R. I. Sutton (Eds) Research in Organizational Behavior, pp. 237-281 (New York: Elsevier Science).

The Climate Group (2005) Carbon Down Profits Up, 2nd edn (Weybridge, London: The Climate Group).

Utting, P. (2002) Regulating business via multi-stakeholder initiatives: a preliminary assessment, in: UNRISD (Ed.) Voluntary Approaches to Corporate Responsibility, pp. 61-126 (Geneva: NGLS).

Wellington, F. and Sauer, A. (2005) Framing Climate Risk in Portfolio Management (Washington, DC: World Resources Institute).

WRI/WBCSD (2004) The Greenhouse Gas Protocol - A Corporate Accounting and Reporting Standard, rev. edn (Washington, DC and Geneva: WRI/WBCSD). 